\title{
Synthesis of $\mathrm{BaTiO}_{3}$ powder from barium titanyl oxalate (BTO) precursor employing microwave heating technique
}

\author{
Y S MALGHE, A V GURJAR ${ }^{\dagger}$ and S R DHARWADKAR* \\ Department of Chemistry, The Institute of Science, 15, Madam Cama Road, Mumbai 400 032, India \\ ${ }^{\dagger}$ Condensed Matter Physics and Materials Science Division, Tata Institute of Fundamental Research, \\ Mumbai 400 005, India
}

MS received 1 March 2004

\begin{abstract}
Cubic barium titanate $\left(\mathrm{BaTiO}_{3}\right)$ powder was synthesized by heating barium titanyl oxalate hydrate, $\mathrm{BaTiO}\left(\mathrm{C}_{2} \mathrm{O}_{4}\right)_{2} \cdot 4 \mathrm{H}_{2} \mathrm{O}$ (BTO) precursor in microwave heating system in air at $500^{\circ} \mathrm{C}$. Heating BTO in microwave above $600^{\circ} \mathrm{C}$ yielded tetragonal form of $\mathrm{BaTiO}_{3}$. Experiments repeated in silicon carbide furnace showed that $\mathrm{BaTiO}_{3}$ was formed only above $700^{\circ} \mathrm{C}$. The product obtained was cubic.
\end{abstract}

Keywords. Ceramics; electronic materials; ferroelectrics; perovskites; microwave synthesis; $\mathrm{BaTiO}_{3}$.

\section{Introduction}

Barium titanate $\left(\mathrm{BaTiO}_{3}\right)$, a high-tech material used for the manufacture of capacitors and sensors is the first of the ceramic type ferroelectrics to be discovered and has been most extensively studied (Mc Quarrie 1955). Doped Ba$\mathrm{TiO}_{3}$ is a strategic material used in different electroceramic devices (Iwaya et al 1983).

Different methods of synthesis of $\mathrm{BaTiO}_{3}$ are reported in the literature. These include (i) conventional ceramic methods (Rase and Roy 1955), (ii) sol gel processes (Hench and Ulrich 1986; Shimooka et al 2000), (iii) modified alkoxide synthesis (Phule and Risbud 1989) and (iv) chemical co-precipitation methods (Clabaugh et al 1956; Potdar et al 1992, 1998; Khollam et al 2002). The temperature of synthesis of $\mathrm{BaTiO}_{3}$ by conventional ceramic technique is relatively higher $\left(>1200^{\circ} \mathrm{C}\right)$ compared to those observed in other methods (Rase and Roy 1955). In a recent publication, Agrawal and co-workers (Agrawal 1998) described the synthesis of $\mathrm{BaTiO}_{3}$ from the mixture of barium carbonate and titanium dioxide employing microwave heating. They observed that hypostoichiometric $\mathrm{TiO}_{2}\left(\mathrm{TiO}_{2-x}\right)$ reacted with $\mathrm{BaCO}_{3}$ in the presence of microwave field at temperature as low as $350^{\circ} \mathrm{C}$ to give the mixture of hexagonal and tetragonal forms of $\mathrm{BaTiO}_{3}$. Increasing the temperature above $800^{\circ} \mathrm{C}$ transformed the hexagonal phase in the mixture completely to the tetragonal form. The same mixture heated in normal resistance furnace could not yield $\mathrm{BaTiO}_{3}$ but produced $\mathrm{Ba}_{2} \mathrm{TiO}_{4}$ above $900^{\circ} \mathrm{C}$. It was further observed that a mixture of $\mathrm{BaCO}_{3}$ and stoichiometric $\mathrm{TiO}_{2}$ heated in microwave up to $900^{\circ} \mathrm{C}$ produced

*Author for correspondence only $\mathrm{Ba}_{2} \mathrm{TiO}_{4}$. Heating the same mixture above $1100^{\circ} \mathrm{C}$ in microwave resulted in the formation of the mixture of $\mathrm{Ba}_{2} \mathrm{TiO}_{4}$ and tetragonal form of $\mathrm{BaTiO}_{3}$. The increased reactivity of non stoichiometric $\mathrm{TiO}_{2}$ was attributed to the most efficient interaction of $\mathrm{TiO}_{2-x}$ (which has anion vacancies) with the microwave field (Agrawal 1998).

The observations of Agrawal and co-workers prompted us to synthesize $\mathrm{BaTiO}_{3}$ powder from the precursor which would generate non stoichiometric $\mathrm{TiO}_{2-x}$ in situ. This would eliminate the need for reduction of titanium dioxide prior to the heat treatment of the mixture of reactants in the microwave field. In the present paper we attempted to synthesize $\mathrm{BaTiO}_{3}$ by heating BTO in microwave heating system. It was felt that the carbon monoxide released during the thermal decomposition of BTO would provide reducing atmosphere to maintain non stoichiometry in the titanium oxide formed during the reaction. $\mathrm{BaTiO}_{3}$ in the cubic form could be synthesized at temperature as low as $500^{\circ} \mathrm{C}$ within an hour using this method. Further heating above $600^{\circ} \mathrm{C}$ induced transformation in the product from cubic to tetragonal form.

\section{Experimental}

\subsection{Synthesis of barium titanyl oxalate (BTO)}

BTO used in the present work was synthesized from the aqueous solution of $\mathrm{Ba}\left(\mathrm{NO}_{3}\right)_{2}(\mathrm{BN})$ and $\mathrm{K}_{2} \mathrm{TiO}\left(\mathrm{C}_{2} \mathrm{O}_{4}\right)_{2}$ (KTO). Both the chemicals were of AnalaR grade. The method consisted of mixing of equimolar aqueous solutions of BN and KTO with constant stirring. The white BTO precipitate obtained was filtered, washed with distilled water and dried in an oven at $50^{\circ} \mathrm{C}$ for $24 \mathrm{~h}$. From chemical analysis, the product could be assigned the molecular formula, $\operatorname{BaTiO}\left(\mathrm{C}_{2} \mathrm{O}_{4}\right)_{2} \cdot 4 \mathrm{H}_{2} \mathrm{O}$. 
2.2 Thermogravimetry (TG), differential scanning calorimetry (DSC) and differential thermal analysis (DTA)

The (TG) as well as (DSC) curves for BTO was recorded in flowing argon at the heating rate of $10^{\circ} \mathrm{C} / \mathrm{min}$ on $9.6 \mathrm{mg}$ sample, employing simultaneous recording TG/DSC SETARAM system (Model 92.16). In addition, differential thermal analysis (DTA) plot for thermal decomposition of BTO was recorded in flowing air at the heating rate of $10^{\circ} \mathrm{C} / \mathrm{min}$ using the instrument supplied by Universal Thermal Analysis Instruments, Mumbai, built to our specifications.

\subsection{Preparation of barium titanate $\left(\mathrm{BaTiO}_{3}\right)$}

The BTO precursor was heated to different temperatures in the range $400-700^{\circ} \mathrm{C}$ employing the microwave heating system fabricated indigenously. The details of microwave system used in the present study are described elsewhere (Borkar and Dharwadkar 2004). The microwave oven used could supply maximum 750 watts input power. The power to the unit could be maintained to a constant set value to fix the desired temperature needed for the experiments, employing the proportional type (PID) temperature controller coupled to a solid state relay (SSR). A shielded chromel-alumel thermocouple was used as a sensor for controlling the input power to the microwave oven at the set temperature. The thermocouple shield had to be grounded to obtain steady temperature values at the set point. The temperature of the sample could be maintained constant to $\pm 1^{\circ} \mathrm{C}$ and measured by a separate calibrated chromel-alumel thermocouple. The influence of microwave field on the measured temperature, if any, was checked by momentarily putting off the microwave oven. No difference was observed in the temperature displayed on the indicator. The sample contained in a cylindrical zirconia crucible was surrounded symmetrically by four silicon carbide rods, which acted as a preheater for the samples poorly interacting with the microwaves at ambient temperature. A schematic of the microwave heating system used in this investigation is shown in figure 1 .

The products obtained after heat treatment of reactants at different temperatures were analysed by X-ray diffraction using SIEMENS X-ray diffractometer (Model D-500) at the scanning speed of $1^{\circ} 2 \theta / \mathrm{min}$. A monochromatized $\mathrm{X}$-ray beam of wavelength $1.5405 \mathrm{~nm}$ was used.

\section{Results}

3.1 Thermogravimetry (TG), differential scanning calorimetry $(D S C)$ and differential thermal analysis (DTA) of BTO

TG and DSC plots recorded for BTO are shown in figure 2. TG curve (figure 2a) shows sequence of four steps with different mass losses involving dehydration and decarboxy- lation. The resulting final product has the stoichiometry corresponding to $\mathrm{BaTiO}_{3}$. The DSC plot for the decomposition recorded in argon (figure $2 b$ ) shows four endothermic peaks corresponding to the reactions (1), (2), (3) and (4). The DTA curve recorded in air (figure 3), shows an endothermic peak followed by a predominately exothermic peak and a sequence of two minor endothermic peaks. From the TG and DTA results it is concluded that the formation of $\mathrm{BaTiO}_{3}$ in air involves the following sequence of steps

$$
\begin{aligned}
& \mathrm{BaTiO}\left(\mathrm{C}_{2} \mathrm{O}_{4}\right)_{2} \cdot 4 \mathrm{H}_{2} \mathrm{O} \rightarrow \mathrm{BaTiO}\left(\mathrm{C}_{2} \mathrm{O}_{4}\right)_{2}+4 \mathrm{H}_{2} \mathrm{O}, \\
& 2 \mathrm{BaTiO}\left(\mathrm{C}_{2} \mathrm{O}_{4}\right)_{2} \rightarrow \mathrm{Ba}_{2} \mathrm{Ti}_{2} \mathrm{O}_{5}\left(\mathrm{CO}_{3}\right)\left(\mathrm{CO}_{2}\right)+ \\
& 2 \mathrm{CO}_{2}+4 \mathrm{CO} \text {, } \\
& \mathrm{Ba}_{2} \mathrm{Ti}_{2} \mathrm{O}_{5}\left(\mathrm{CO}_{3}\right)\left(\mathrm{CO}_{2}\right) \rightarrow \mathrm{Ba}_{2} \mathrm{Ti}_{2} \mathrm{O}_{5}\left(\mathrm{CO}_{3}\right)+\mathrm{CO}_{2}
\end{aligned}
$$

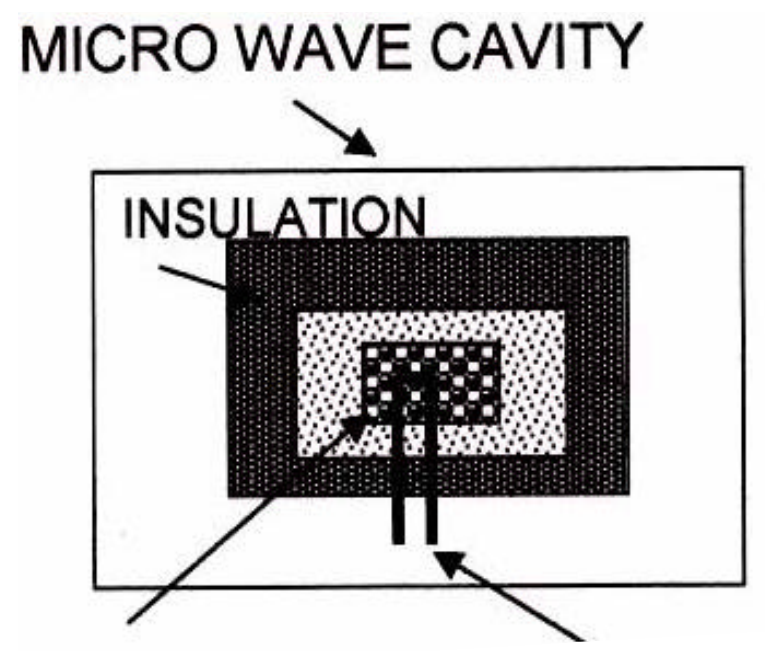

\section{SAMPLE THERMOCOUPLE}

Figure 1. Schematic of microwave heating system.

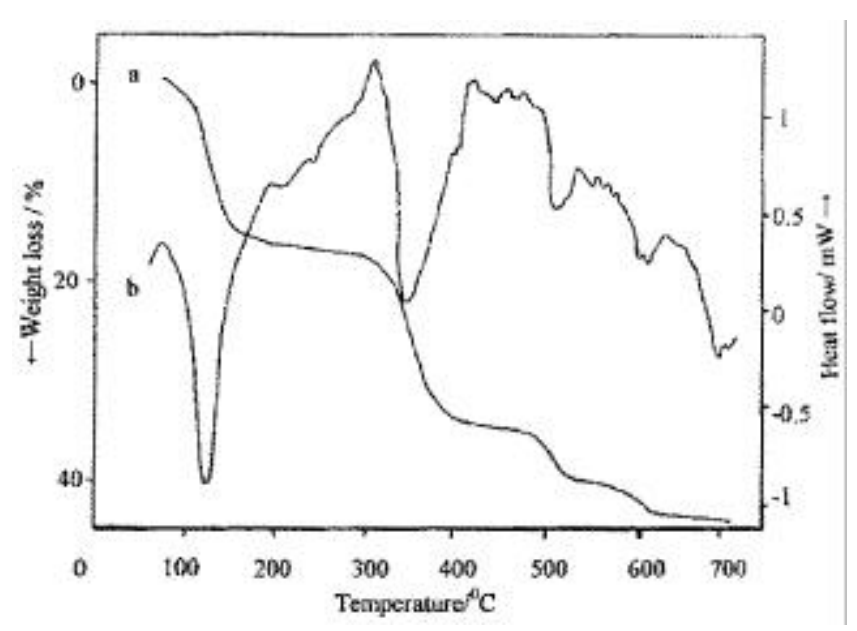

Figure 2. TG (a) and DSC (b) curves of BTO recorded in argon atmosphere. 


$$
\begin{aligned}
& \mathrm{Ba}_{2} \mathrm{Ti}_{2} \mathrm{O}_{5}\left(\mathrm{CO}_{3}\right) \rightarrow 2 \mathrm{BaTiO}_{3}+\mathrm{CO}_{2}, \\
& \mathrm{CO}+1 / 2 \mathrm{O}_{2} \rightarrow \mathrm{CO}_{2} .
\end{aligned}
$$

The steps representing the formation of $\mathrm{BaTiO}_{3}$ from BTO concluded from the present studies are identical to those reported by Gopalkrishnamurthy and coworkers (1975).

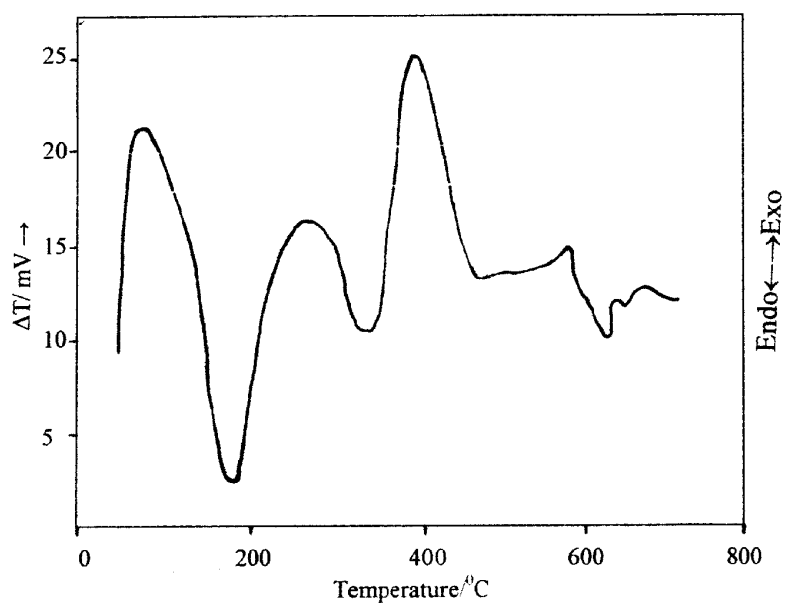

Figure 3. DTA curve of BTO recorded in air.

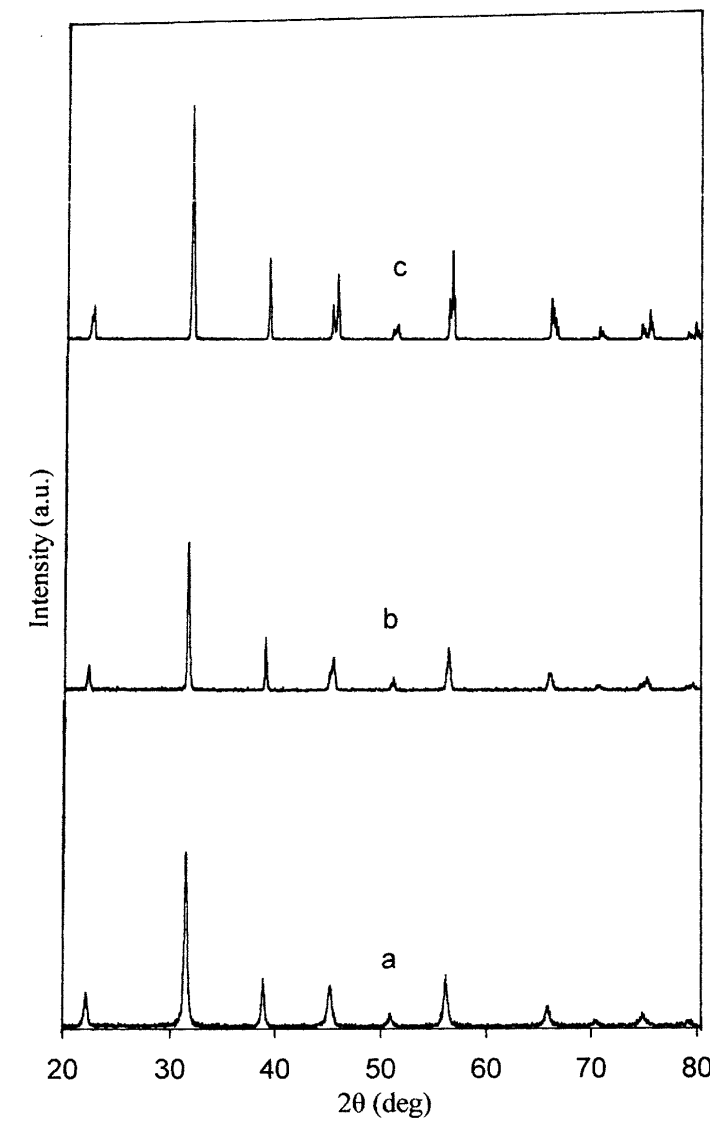

Figure 4. XRD patterns of BTO calcined in microwave heating system at (a) 500 , (b) 600 and (c) $700^{\circ} \mathrm{C}$ for $1 \mathrm{~h}$.
It could be concluded from the TG curve that the formation of BT from the precursor was complete by $600^{\circ} \mathrm{C}$. It is interesting to note that in the second step of decomposition of BTO carbon monoxide is evolved as the gaseous product which could provide reducing atmosphere in the vicinity of the sample.

\section{$3.2 \quad X$-ray diffraction patterns}

The X-ray diffraction patterns of the product of thermal decomposition of BTO in microwave heating system in the temperature range $500-700^{\circ} \mathrm{C}$ are presented in figure 4 . It is observed that formation of $\mathrm{BaTiO}_{3}$ from BTO is complete at $500^{\circ} \mathrm{C}$. The product at $500^{\circ} \mathrm{C}$ consists of pure cubic $\mathrm{BaTiO}_{3}$. The product obtained at $600^{\circ} \mathrm{C}$, however, indicates that the cubic form possibly transforms to tetragonal structure as revealed by asymmetry introduced in peaks at the $2 \theta$ values corresponding to $45 \cdot 25,50 \cdot 90,56 \cdot 12,74 \cdot 87$ and 79.5 , respectively. The splitting of these peaks in the sample heated at $700^{\circ} \mathrm{C}$ and above confirmed the transformation of cubic phase to a tetragonal form.

\section{Discussion}

The results presented in the foregoing sections indicate that $\mathrm{BaTiO}_{3}$ in the cubic form could be synthesized by heating BTO at temperature as low as $500^{\circ} \mathrm{C}$. The reducing atmosphere provided by the evolved carbon monoxide (2) could perhaps be responsible to yield non stoichiometric $\mathrm{TiO}_{2}$ which subsequently reacted at low temperatures to form $\mathrm{BaTiO}_{3}$. The product obtained began to transform to

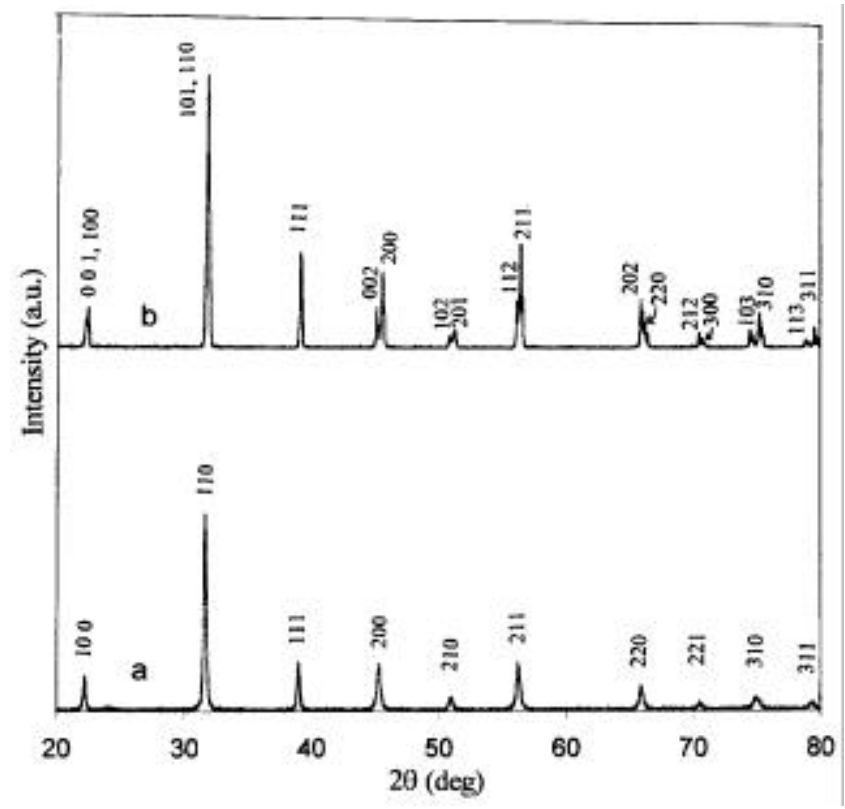

Figure 5. XRD patterns of BTO calcined in (a) silicon carbide furnace and (b) microwave heating system at $700^{\circ} \mathrm{C}$ for $1 \mathrm{~h}$. 
the tetragonal phase above $600^{\circ} \mathrm{C}$. The transformation was complete at $700^{\circ} \mathrm{C}$. This is revealed by splitting of several lines present in the X-ray pattern of the cubic phase into doublets, mentioned earlier.

The other important aspect which emerged from this investigation is the fact that BTO precursor on decomposition in air yielded pure product, $\mathrm{BaTiO}_{3}$ at $700^{\circ} \mathrm{C}$ irrespective of mode of heating. The crystallographic forms obtained in the two cases are, however, different (figure $5)$. The product obtained by heating the BTO precursor in silicon carbide furnace at $700^{\circ} \mathrm{C}$ in air was cubic. $\mathrm{BaTiO}_{3}$ could not be, however, obtained in any crystallographic form by heating BTO in silicon carbide furnace in air below $650^{\circ} \mathrm{C}$.

Our present observations indicate that the lowering of reaction temperature in microwave heating could be the result of two independent factors, which, besides the interaction of microwave with defects, could also involve the role of oxygen vacancies in solid state reaction. This is borne out from the fact that at $700^{\circ} \mathrm{C}$ the BTO transforms to $\mathrm{BaTiO}_{3}$ even in the absence of microwave field. It is felt that evolution of $\mathrm{CO}$ in the decomposition of BTO creates reducing atmosphere in the vicinity of the sample which could be sufficient to yield hypostoichiometric $\mathrm{TiO}_{2}$ facilitating the solid state reaction at much lower temperature.

\section{Conclusions}

The results obtained in this investigation show that $\mathrm{Ba}$ $\mathrm{TiO}_{3}$ in the cubic form could be synthesized from BTO at temperature as low as $500^{\circ} \mathrm{C}$. Thermal decomposition of BTO presumably yields hypostoichiometric $\mathrm{TiO}_{2}$ by virtue of the presence of evolved $\mathrm{CO}$ in the reaction, which in the presence of the microwave field combines with $\mathrm{BaO}$ to yield the cubic phase. The cubic $\mathrm{BaTiO}_{3}$ transformed completely to the tetragonal form on heating it in the microwave field above $700^{\circ} \mathrm{C}$.

In the recent studies (Potdar et al 1998; Khollam et al 2002), it was reported that BTO on heating in the resis- tance heated furnace above $700^{\circ} \mathrm{C}$ in air produced cubic form of BT. Our present observations are in agreement with these results. The cubic form was transformed to tetragonal structure in the pellets sintered in air above $1250^{\circ} \mathrm{C}$ (Potdar et al 1998; Khollam et al 2002). The production of tetragonal form of $\mathrm{BaTiO}_{3}$ at low temperatures following the present procedure could provide considerable edge over other existing processes and make it economically much more viable for commercial exploitation.

\section{Acknowledgements}

Authors are thankful to Mr N A Kulkarni and Mr V M Chopade, TIFR, Mumbai, for recording the XRD patterns of the sample. One of the authors (YSM) is also thankful to the University of Mumbai, Mumbai, for financial support.

\section{References}

Agrawal D K 1998 Current Opinion Solid State \& Materials Science 3480

Borkar S A and Dharwadkar S R 2004 Ceram. Int. 30509

Clabaugh W S, Swigbard E M and Gilchrist R 1956 J. Res. Nat. Bur. Std. U556 298

Gopalkrishnamurthy H S, Subbarao M and Kutty T R N 1975 J. Inorg. Nucl. Chem. 37891

Hench L and Ulrich D R 1986 Science of ceramic and chemical processing (New York: Wiley-Interscience)

Iwaya S, Masumura M, Midori Y, Oikawa Y and Abe H 1983 US Pat. No. 4404209

Khollam Y B, Deshpande A S, Potdar H S, Deshpande S B, Date S K and Patil A J 2002 Mater. Letts 55175

Mc Quarrie M 1955 Ceram. Bull. 34225

Phule P P and Risbud S H 1989 Mater. Sci. Engg. 133241

Potdar H S, Deshpande S B, Godbole P D and Date S K 1992 Indian J. Chem. A31 870

Potdar H S, Deshpande S B, Sainkar S R, Mitra A and Date S K 1998 Indian J. Chem. A37 674

Rase D E and Roy R 1955 J. Am. Ceram. Soc. 3891

Shimooka S, Kohiki S, Kobayasi T and Kuwabara M $2000 \mathrm{~J}$. Mater. Chem. 101511 